\title{
Уточнение оценок распределения температуры горных пород литосферы на основе данных глубинных электромагнитных зондирований
}

\author{
Шевцов А.Н. ${ }^{1,2}$ \\ ${ }^{1}$ Геологический институт КНЦ РАН, Anamumbl, anshev2019-01@mail.ru \\ ${ }^{2}$ Мурманский Арктический государственный университет (Апатитский филиал), Anатитьл
}

Аннотация. В работе на примере результатов глубинных электромагнитных зондирований с контролируемым источником и аудио-магнитотеллурических измерений экспериментов FENICS-2007, 2009 и 2014 представлена методика определения температуры горных пород земной коры и верхней мантии на основе решения обратной задачи электромагнитного зондирования для двухфазной модели электропроводности горных пород и с учетом лабораторных данных об электропроводности горных пород при высоких температурах (Пархоменко, Бондаренко, 1972). Зондирования с естественными и мощными контролируемыми источниками выполнены в пределах крупных плохо проводящих блоков литосферы, так называемых «окон прозрачности» с учетом влияния волновода «Земля-ионосфера» и влияния приповерхностных проводников (статического сдвига). Полученные кривые кажущегося сопротивления и фазы импеданса имеют преимущественно плавное изменение вдоль профилей наблюдений и это позволяет выполнять интерпретацию в рамках одномерных моделей. Моделирование температуры выполнено в предположении, что в пределах верхней части разреза (на глубинах менее 20-30 км) изменения удельного сопротивления с глубиной обусловлены влиянием пористости, проницаемости, влажности и минерализации поровых растворов. Для глубин более 20-30 км принято, что сопротивление нижней части земной коры и верхней мантии определяется, прежде всего, минеральным составом «сухих» горных пород, температурой и давлением. Изменение минерального состава литосферы с глубиной принято на основании априорных геологических оценок и сверхглубокого бурения. Моделирование распределения температуры по глубине выполняется на основе уравнения теплового баланса (Шафанда и др., 1987). Рассчитанные температурные модели сопоставлены с моделью (Глазнев, 2003), построенной по результатам комплексной интерпретации геофизических данных без учета результатов электромагнитных исследований.

Ключевые слова: электропроводность, электромагнитное зондирование, температура, тепловой поток.

\section{Refinement of estimates of the temperature distribution of rocks in the lithosphere based on the data of deep electromagnetic sounding}

\author{
Shevtsov A.N. ${ }^{1,2}$ \\ ${ }^{1}$ Geological Institute, KSC RAS, Apatity, anshev2019-01@mail.ru \\ ${ }^{2}$ Murmansk Arctic State University (Apatity branch), Apatity
}

\begin{abstract}
Using the results of deep electromagnetic sounding with a controlled source and audiomagnetotelluric measurements of the FENICS-2007, 2009 and 2014 experiments as an example, a technique is presented for determining the temperature of rocks in the earth's crust and upper mantle based on solving the inverse problem of electromagnetic sounding for a two-phase model of electrical conductivity of rocks and with taking into account laboratory data on the electrical conductivity of rocks at high temperatures (Parkhomenko, Bondarenko, 1972). Soundings with natural and powerful controlled sources were performed within large poorly conducting blocks of the lithosphere, the so-called «transparency windows», taking into account the influence of the «Earth-ionosphere» waveguide and the influence of near-surface conductors (static shear). The obtained curves of apparent resistivity and impedance phase have predominantly smooth variation along the observation profiles and this allows interpretation within the framework of one-dimensional models. Temperature modeling was carried out on the assumption that within the upper part of the section (at depths less than 20-30 km), changes in resistivity with depth are due to the influence of porosity, permeability, moisture and salinity of pore solutions. For depths of more than $20-30 \mathrm{~km}$, it is assumed that the resistance of the lower part of the earth's crust and upper mantle is determined, first of all, by the mineral composition of «dry» rocks, temperature and pressure. The change in the mineral composition of the lithosphere with depth was taken on the basis of a priori geological estimates and superdeep drilling. The temperature distribution over depth is modeled on the basis of the heat balance equation (Shafanda et al., 1987). The calculated temperature models are compared with the model (Glaznev, 2003), built on the basis of the results of complex interpretation of geophysical data without taking into account the results of electromagnetic studies.
\end{abstract}

Key words: electrical conductivity, electromagnetic sensing, temperature, heat flux. 


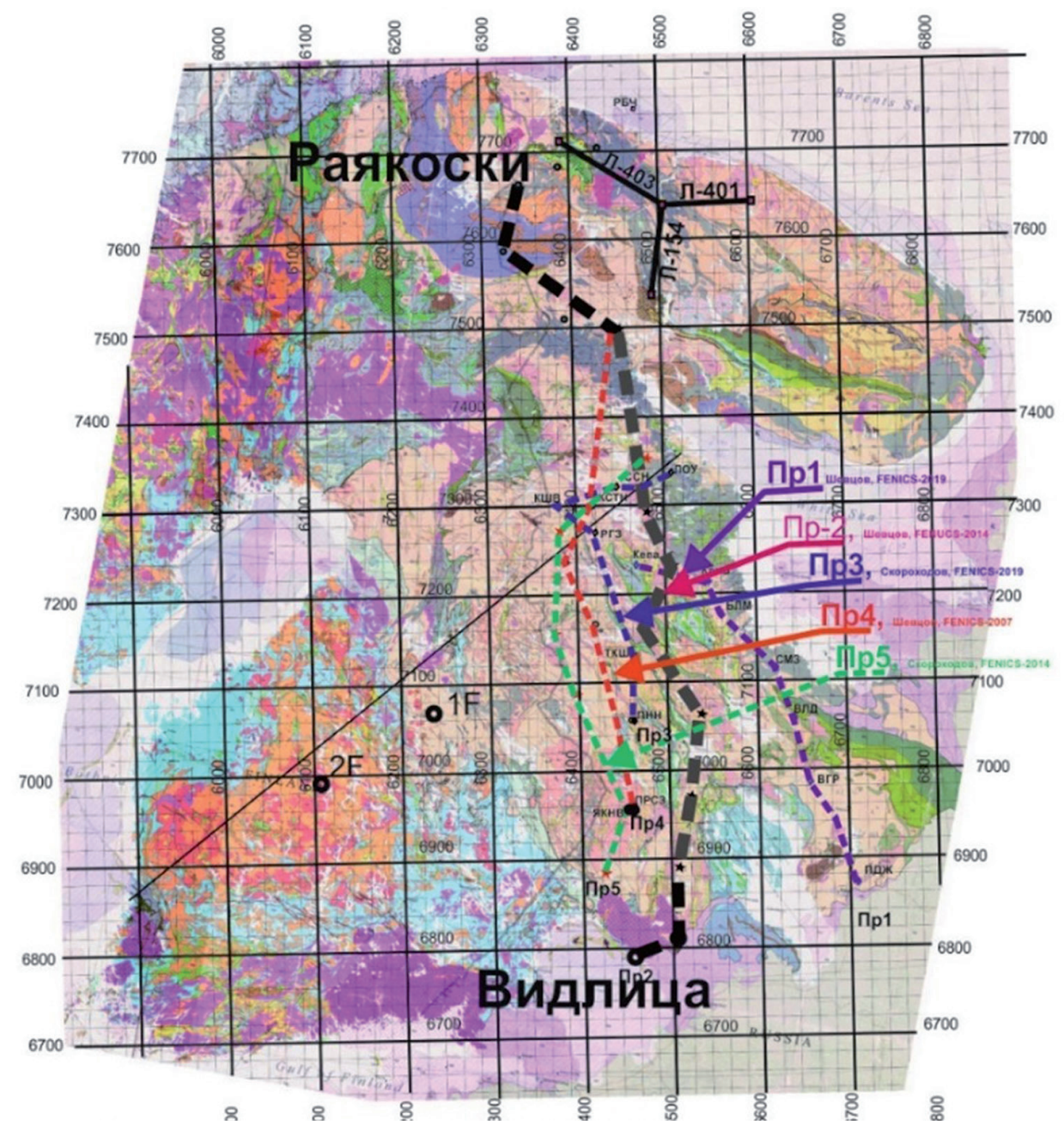

Рис. 1 Схема положения питающих линий и профилей экспериментов FENICS-2007, 2009, 2014 и 2019 и профиль Раякоски - Видлица.

Fig. 1. Location of sources lines and profiles of the experiments FENICS-2007, 2009, 2014, 2019 and profile Rayakosky - Vidlitsa.

\section{Введение}

В период 2004-2019 Геологическим институтом в тесном сотрудничестве с Центром физикотехнических проблем энергетики Севера и при поддержке РФФИ, под руководством А.А. Жамалетдинова, организовано и проведено несколько этапов уникального эксперимента по использованию заземленных участков промышленных линий электропередачи в качестве контролируемого источника электромагнитного поля совместно с измерениями естественного аудио-магнитотеллурического поля для проведения глубинных зондирований литосферы восточной части Фенноскандинавского щита (эксперименты FENICS-2007, 2009, 2014 и 2019). Благодаря большой протяженности используемых участков ЛЭП 401 (109 км), ЛЭП 153/154 (105 км) и ЛЭП 403 (129 км) в ходе экспериментов удалось провести зондирование в диапазоне частот 0.382 - 200 Гц, на удалениях до 847 км от центра питающей линии (рис. 1).

Наряду с данными частотного и зондирования с дипольными установками в ЦентральноФинляндском гранитоидном массиве, Енско-Ковдорском блоке (Жамалетдинов и др. 2017), а так же дистанционного и частотного зондирования на Мурманском блоке (Шевцов и др., 2017, Жамалетдинов и др., 2019) эксперименты FENICS подтвердили применимость модели «нормального» геоэлектрического разреза, впервые предложенной в 1998 году А.А. Жамалетдиновым для интерпретации результатов глубинного электромагнитного зондирования однородных по латерали плохо 
проводящих древнейших блоков литосферы Фенноскандинавского щита. В этой, достаточно простой, пятислойной модели с промежуточным проводящим слоем дилатантно-диффузионной природы в интервале глубин 3-10 км с продольной проводимостью в 0.1-0.5 См и плохо проводящим слоем на глубинах 20-40 км с поперечным сопротивлением $5 \cdot 10^{9}-10^{10} \mathrm{Oм} \mathrm{м}^{2}$, глубже границы Мохо на глубинах 60-120 км наблюдается понижение удельного сопротивления обусловленное высокими значениями температуры (свыше $700^{\circ} \mathrm{C}$ на глубине 100 км). При этом слои 1-3 можно представить как хрупкие, квазиупругие, в которых наблюдаются трещины и разломы заполненные флюидом метеорного происхождения, слои 4 и 5 квазипластичные - непроницаемые для флюидов.

\section{Физические основы определения температуры по геоэлектрическим данным}

Для интерпретации результатов на больших глубинах потребовалось привлечь имеющиеся данные по распределению температуры с глубиной и зависимости удельного сопротивления горных пород от температуры.

Более детальные оценки выполняются на основе расчетов уравнения теплового баланса с учетом тех или иных предположений о распределении источников энергии в Земле и о теплофизических свойствах отдельных ее слоев. После введения ряда упрощений (пренебрежение конвекцией, кривизной Земли, стационарное приближение) уравнение теплового баланса можно записать как:

$$
\frac{\partial Q(z)}{\partial z}=q(z)
$$

где $q(z)$ - коэффициент теплогенерации, измеряемый в единицах [мкВт/м³], и $Q(z)-$ плотность те-

плового потока $\left[\mathrm{BT} / \mathrm{M}^{2}\right]$ на глубине z.

$$
Q(z)=\lambda(z) \cdot G(z), G(z)=\frac{\partial T(z)}{\partial z},
$$

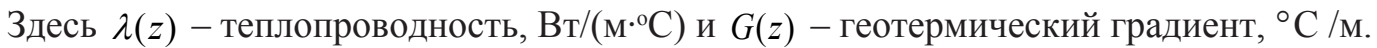

Методы расчета температуры в Земле на основе уравнения теплового баланса различаются способами задания априорных сведений о теплогенерации и теплопроводности горных пород. В работе (Шафанда и др. 1987) для этой цели использована слоистая одномерная модель, в которой послойно определяются ·радиогенная генерация тепла, связанная со средним поверхностным тепловым потоком, изменяющимся с глубиной по экспоненциальному закону до глубины 120 км. Глубже радиоактивность мантии принята постоянной. Эффективная теплопроводность рассчитывается также по линейному закону, учитывающему рост ее с глубиной. Рассчитанная таким образом кривая распределения температуры с глубиной для областей с тепловым потоком $40 \mathrm{mBT} / \mathrm{M}^{2}$ (среднее значение для Фенноскандинавского щита) приведена на рисунке 3 (кривая 4). В работе (Глазнев и др. 1987) предложен способ расчета теплогенерации на глубине с помощью сейсмических данных. Подход основан на использовании корреляционной зависимости между уменьшением теплотворной способности пород с глубиной $q(z)$ и увеличением скорости прохождения продольных волн $\mathrm{Vp}(\mathrm{z})$ относительно Vcp для верхней части коры. На рис. 3 представлена кривая изменения температуры с глубиной для Фенноскандинавского щита (кривая 6), рассчитанная на основе описанного подхода (Глазнев и др., 1987). Теплопроводность пород верхней части коры принята в пределах (1.5-3) Вт/(м $\left.{ }^{\circ} \mathrm{C}\right)$. Наблюдается уменьшение теплопроводности с ростом температуры $(10 \%$ на каждые $\left.100^{\circ} \mathrm{C}\right)$ и увеличение ее с ростом основности $\left(3.5 \mathrm{BT} /\left(\mathrm{M}^{\circ} \mathrm{C}\right)\right.$ на глубине 300 км).

Проводимость горных пород будем описывать в рамках двухфазной модели (Ваньян, 1997). При этом вмещающая порода - матрица, в порах которой находится проводящий флюид, имеет высокое удельное сопротивление. Электропроводность жидкой фазы определяется главным образом минерализацией, температурой и давлением. Для водного раствора связь минерализации и удельного сопротивления $\rho$ приближенно может быть описана обратно-пропорциональной функцией концентрации концентрации соли С (г/л) в растворе (Алексанова и др., 2005): 


$$
\rho_{S}=\frac{K}{C}
$$

Здесь $K=$ const, зависит от химического состава - для поваренной соли $K_{\mathrm{NaCl}}=8$ Ом м г/л. (Огильви, 1990)

В зависимости от температуры удельное сопротивление жидкой фазы при небольших давлениях определяется линейной зависимостью (Ваньян, 1997)

$$
\frac{\Delta \rho_{S}}{\rho_{S 18}}=\frac{\rho_{S}-\rho_{S 18}}{\rho_{S 18}}=-\alpha\left(t-18^{0} C\right)
$$

Где величина $\alpha \approx 0.025$.

Электропроводность раствора при высоких Т-р параметрах имеет сложную нелинейную связь с температурой. Например, согласно (4) при температуре $400^{\circ} \mathrm{C}$ электропроводность может увеличиться более чем в 10 раз, однако если давление при этом не превышает 2 кБар, увеличение составит всего 5 раз. При этом (4) будет определять предельное максимальное изменение сопротивления.

Удельное сопротивление твердой фазы - вмещающей породы описывается законом Иоффе (Иоффе, 1974) -

$$
\rho_{M}=\rho_{0} \exp \left(\frac{E_{a}}{k_{B} T}\right)
$$

где $\rho_{0}-$ предэкспоненциальный коэффициент, численно равный удельному сопротивлению горной породы при $T \rightarrow \infty ; E_{a}$ - энергия активации ионов, осуществляющих ток (в электрон-вольтах, 1 эB $=1.602 \cdot 10^{-19}$ Дж); $k_{B}$ - постоянная Больцмана $\left(k_{B}=1.38 \cdot 10^{-23}\right.$ Дж/град); $T$ - абсолютная температуpa $(\mathrm{K})$ по шкале Кельвина. Параметры $\rho_{0}$ и $E_{a}$ определялись по данным измерений на сухих образцах (Пархоменко, 1965, Пархоменко, Бондаренко, 1972).

Суммарное сопротивление горной породы в верхней части разреза ( $\mathrm{H}<10$ км) определялось по закону Арчи, для заданных параметров минерализации и температуры

$$
\rho_{\text {eff }}=k_{p}^{-2} \cdot \rho_{S}
$$

Теперь можно определять параметры модели земной коры по результатам решения обратной задачи для электромагнитных данных, например, по объединенной модели разреза электропроводности для магнитотеллурических (МТ) данных и данных, измеренных с контролируемым источником (CSAMT), при предполагаемой литологии и с учетом лабораторных данных для проводимости горных пород. Для этого, в одномерном случае, воспользуемся функционалом невязки (7) для измеренных значений логарифма кажущегося сопротивления $\lg \rho_{\omega j}^{1}$ и фазы - аргумента импеданса $\arg \left(Z_{\omega j}^{1}\right)$ для ј-ой частоты $\omega_{j}$ и решением прямой задачи:

$$
\begin{aligned}
S(\rho)= & \sum_{j=1}^{N}\left(\lg \rho_{\omega j}^{0}(\rho)-\lg \rho_{\omega j}^{1}\right)^{2}+ \\
& +\sum_{j=1}^{N}\left(\arg \left(Z_{\omega j}^{0}(\rho)\right)-\arg \left(Z_{\omega j}^{1}\right)\right)^{2}=\min
\end{aligned}
$$

Здесь $\rho_{\omega j}^{0}$ - кажущееся сопротивление и $\arg \left(Z_{\omega j}^{0}(\rho)\right)$ - фаза импеданса, рассчитанные для модели геоэлектрического разреза $\rho(z)$. Минимизируем невязку (7) и определяем удельное сопротивление $\rho(z)$, на основе решения уравнения баланса (1) - при заданных граничных условиях на поверхности: плотность теплового потока $Q(0)=Q_{0}$ и температура $T(0)=T_{0}$, кроме того, полагая известной зависимость теплопроводности с глубиной и температурой: $\lambda(z)=\lambda_{0}(z, T)$. При этом 
удельное сопротивление рассматривается как функционал заданных граничных условий, функции теплопроводности $\lambda(z)=\lambda_{0}(z, T)$ и температуры $T(z)$, которые уточняются в процессе минимизации невязки (7).

\section{Профиль Раякоски - Видлица}

Используя данные экспериментов FENICS-2009 и 2014 года, а также сведения по тепловому потоку путем сведения результатов одномерной инверсии в каждой из точек профиля построен геотермический профиль Раякоски - Видлица (рис. 1) в субмеридиональном направлении через Карело-Кольский участок Фенноскандинавского щита (рис. 2 a). На рисунке 26 показан геотермический разрез для данного профиля, полученный путем интерполяции комплексной 3D модели В. Н. Глазнева построенной ранее (Глазнев, 2003).

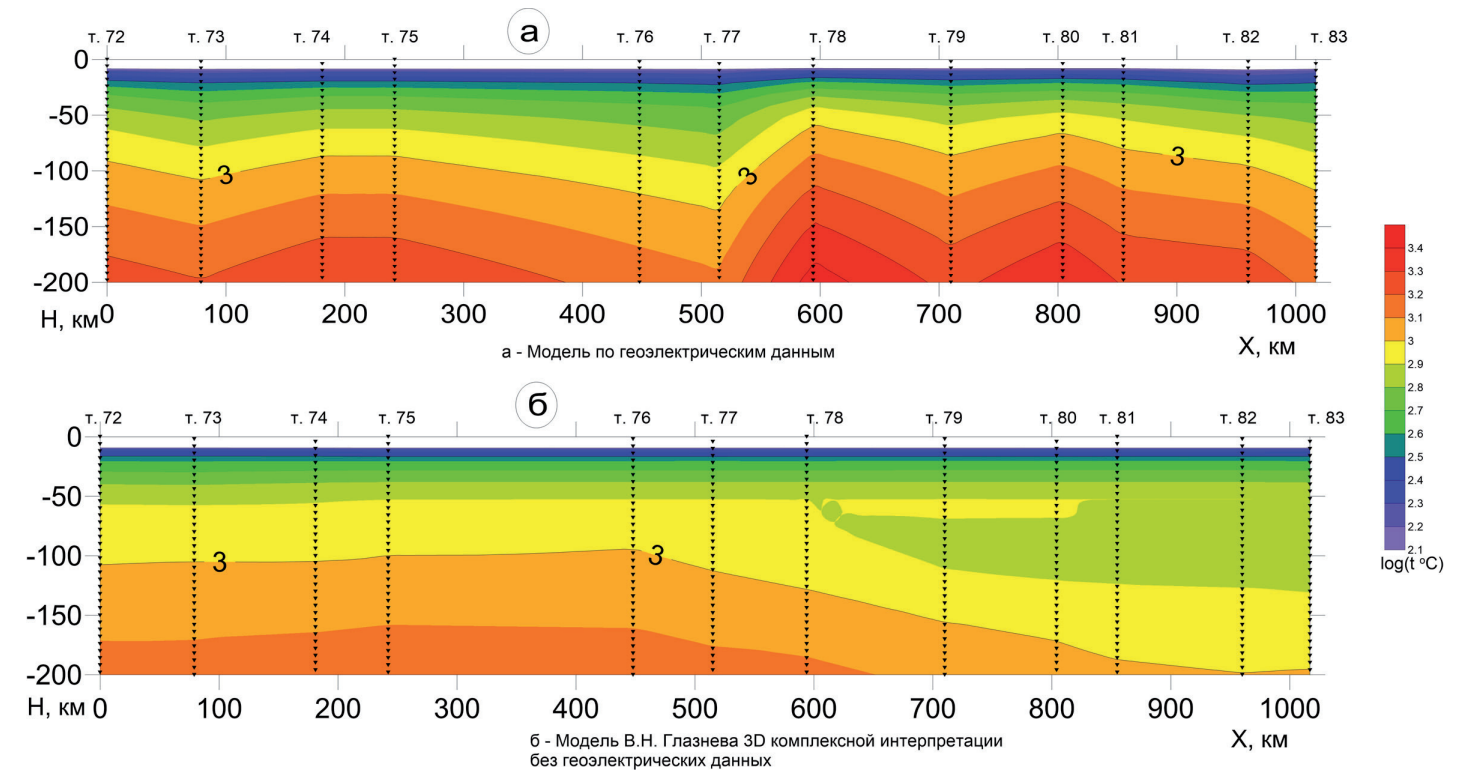

Рис. 2. Геотермический профиль Раякоски - Видлица. а - по результатам инверсии данных электромагнитных зондирований и теплового потока, б - по модели В.Н. Глазнева (Глазнев, 2003).

Fig. 2. Geothermal profile of Rayakoski-Vidlitsa. a-according to the results of inversion of the data of electromagnetic soundings and heat flux, $\mathrm{b}$ - according to the model of V.N. Glazneva (Glaznev, 2003).

\section{Заключение}

В статье представлен алгоритм оценки температурной зависимости от глубины с использованием информации, предоставленной а-priori об изменении электрической проводимости с глубиной (на основе результатов электромагнитных зондирований) и электрической проводимости и состава пород на глубине (на основе лабораторных данных и геологических предположений). Решение проблемы иллюстрируется на примере расчетов, выполненных для профиля Раякоски - Видлица. Информация об электропроводности получена по результатам электромагнитных зондирований с промышленными линиями электропередачи (эксперимент FENICS) и по измерениям магнитотеллурического поля в различных частях Фенноскандинского щита. Отмечается хорошее согласие построенного геотермического разреза с моделью В.Н. Глазнева в северной части профиля и существенные расхождения в южной части, которые возможно, обусловлены ограничениями одномерных моделей. Дальнейшее развитие предлагаемого подхода связано с использованием двумерных алгоритмов решения обратной задачи для данных электромагнитного зондирования, так и для решения уравнения баланса.

Работа выполнена при финансовой поддержке РФФИ, проект № 018-05-00528, а также в рамках госзадания Министерства образования и науки РФ - тема ГИ КНЦ РАН № 0226-2019-0052. 


\section{Литература}

1. Алексанова Е.Д., Бобачев А.А., Большаков Д.К., Горбунов А.А., Иванова С.В., Куликов В.А., Модин И.Н., Пушкарев П.Ю., Хмелевской В.К., Шустов Н.Л., Яковлев А.Г. Электроразведка: Пособие по электроразведочной практике для студентов геофизических специальностей (под ред. В.К. Хмелевского, И.Н. Модина, А.Г. Яковлева). М. 2005. 311 с.

2. Ваньян Л.Л. Электромагнитные зондирования. М. Изд-во: Научный мир. 1997. 218 с. ISBN 5-89176-018-5.

3. Глазнев В.Н. Комплексные геофизические модели фенноскандской литосферы. Апатиты. Изд-во: «КиМ». 2003. 252 с.

4. Иоффе А.Ф. Избранные вопросы. Механические и электрические свойства кристаллов. Т. 1. Ленинград. Изд-во: Наука. 1974. 326 с.

5. Огильви И.И. Основы инженерной геофизики. М. Изд-во: Недра. 1990. 501 с. ISBN 5-247-01414-6.

6. Жамалетдинов А.А., Велихов Е.П., Шевцов А.Н., Колобов В.В., Колесников В.Е., Скороходов А.А., Короткова Т.Г., Ивонин В.В., Рязанцев П.А., Бирулы М.А. Эксперимент «Ковдор-2015»: исследование параметров проводящего слоя дилатансно-диффузионной природы (Слой DD) в архейском кристаллическом фундаменте Балтийского щита. Доклады наук о Земле. 2017. T. 474. С. 641-645. https://doi. org/10.1134/S1028334X17060095.

7. Жамалетдинов А.А., Велихов Е.П., Шевцов А.Н., СкороходовА.А., Колобов В.В., Ивонин В.В., Колесников В.В. Эксперимент «Мурман-2018» по дистанционному зондированию с целью исследования границы «непроницаемости» на переходе между хрупким и пластичным состояниями кристаллической земной коры // ДАН. 2019. Т. 486. № 3. С. 91-96.

8. Пархоменко Э.И. Электрические свойства горных пород. М. Изд-во: Наука. 1965. 164 с.

9. Пархоменко Э.И., Бондаренко А.Т. Электрическая проводимость пород при высоком давлении и температурах. Л. Изд-во: Недра. 1972. 279 с.

10. Шафанда Дж., Чермак В., Биодри Л. Методы расчета распределения глубины температур // Изучение литосферы с использованием геофизических методов. Ч. 2. Киев. 1987. С. 102-118.

11. Шевцов А.Н., Жамалетдинов А.А., Колобов В.В., Баранник М.Б. Частотное электромагнитное зондирование с промышленными ЛЭП на Карело-Кольском геотраверсе // Записки Горного института. 2017. T. 224. C. 178-188. https://doi.org/10.18454/PMI.2017.2.178. 